\title{
PANORAMA DE LA FRONTERA ENTRE COLOMBIA Y PANAMÁ: \\ FLUJOS MIGRATORIOS E ILEGALIDAD EN EL DARIÉN
}

Sebastián Polo Alvis

Enrique Serrano López

Laura Manrique Lara

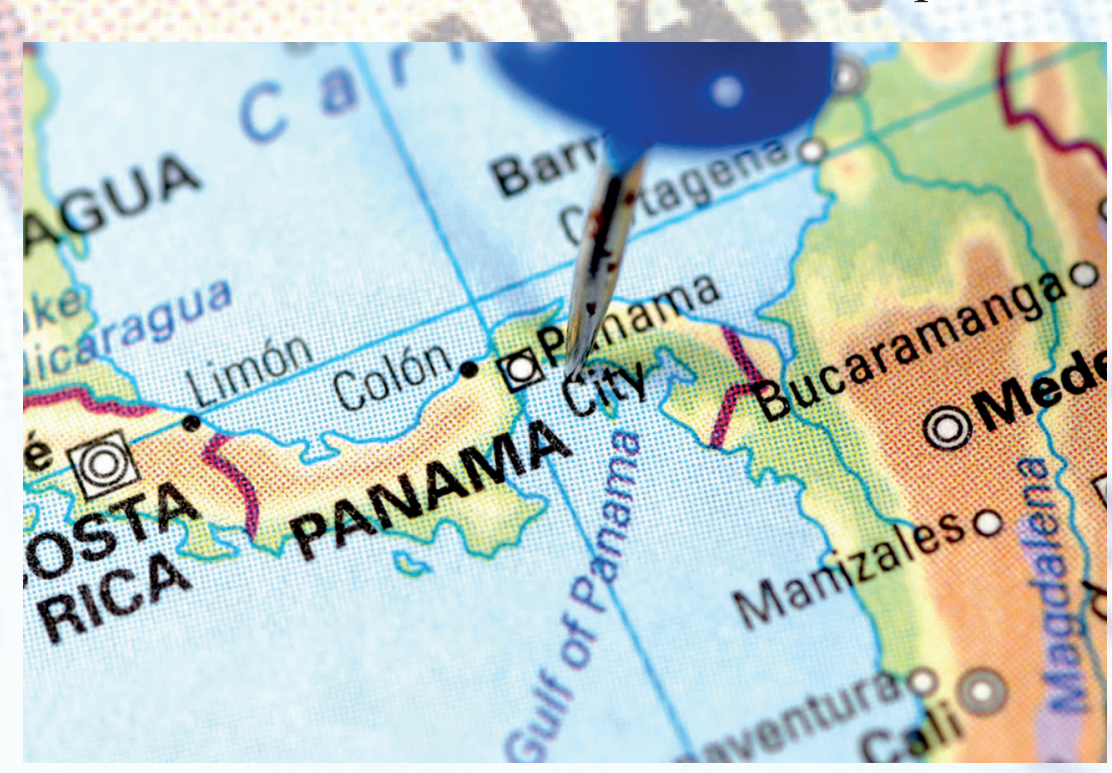





\title{
PANORAMA DE LA FRONTERA ENTRE COLOMBIA Y PANAMÁ: FLUJOS MIGRATORIOS E ILEGALIDAD EN EL DARIÉN*
}

\author{
Sebastián Polo Alvis \\ Enrique Serrano López \\ Laura ManriQue Lara \\ UNIVERSIDAD DEL ROSARIO
}

\section{Resumen}

Este artículo busca hacer un estudio del estado actual de la migración entre Colombia y Panamá, incluyendo la migración legal y la migración irregular. Para ello, se genera una identificación de los factores que han impulsado y atraído a los distintos grupos de colombianos y personas de otras nacionalidades a cruzar la frontera colombo-panameña, y se profundiza en la situación social y legal enfrentada por esta población en territorio panameño. Adicionalmente, se procede con el estudio a profundidad de la dinámica del tráfico ilícito de migrantes que opera en la zona fronteriza, y se resalta las posiciones estatales colombiana y panameña frente al tema migratorio, en las que han puesto el énfasis en el riesgo a la seguridad del Estado y menos interés a la situación de vulnerabilidad en la que se pueden encontrar las personas migrantes.

Palabras clave: migraciones, Colombia, Panamá, tráfico ilícito de migrantes, trata de personas, América Latina.

Los autores: Sebastián Polo Alvis, profesor de cátedra y coordinador del semillero Migraciones colombianas al exterior, Universidad del Rosario. Correo electrónico: sebastian.polo@urosario.edu.co

Enrique Serrano López, profesor de planta, investigador y director del semillero Migraciones colombianas al exterior, Universidad del Rosario. Correo electrónico: enrique.serrano@urosario.edu.co

Laura Manrique Lara, joven investigadora del proyecto de relaciones China-América Latina y del semillero Economía política internacional colombiana, Universidad del Rosario. Investigadora adjunta del semillero Migraciones colombianas al exterior. Correo electrónico: laura.manrique@@urosario.edu.co

Recibido: 25 de julio de 2018; evaluado: 25 de agosto de 2018; aceptado: 27 de agosto de 2018

La presente investigación se adelantó en el semillero Migraciones colombianas al exterior (Semicoex) de la Universidad del Rosario. Los autores agradecen a Carolina Bernal-Márquez por su colaboración para la realización de este artículo. 


\title{
OVERVIEW OF THE COLOMBIA-PANAMA BORDER: MIGRATION FLOWS AND ILLEGALITY IN THE DARIEN
}

\author{
Sebastián Polo Alvis \\ ENRIQUe SERrano López \\ LAUra ManriQue Lara \\ UNIVERSIDAD DEL ROSARIO
}

\begin{abstract}
This paper aims to study the current flow of migrations from Colombia to Panama, both legal and illegal. In order to achieve this, several factors that drive migration have been identified in populations from Colombia and other countries, as well as their social and legal situation while crossing the border. Additionally, this paper analyzes in depth the logic and dynamics of migrant smuggling in the border area, highlighting the fact that migratory policy in Panama and Colombia emphasize national security risks rather than the vulnerability of these populations.
\end{abstract}

Keywords: migrations, Colombia, Panama, border, migrant smuggling, trafficking in persons, Latin America.

About the authors: Sebastián Polo Alvis, Adjunct Professor and Coordinator of the Research Incubator "Colombian Migrations Abroad," Universidad del Rosario. Email: sebastian.polo@urosario.edu.co

Enrique Serrano López, Associate Professor, Researcher and Director of the Research Incubator "Colombian Migrations Abroad," Universidad del Rosario. Email: enrique.serrano@urosario.edu.co

Laura Manrique Lara, researcher of the project "Relations between China and Latin America" and the Research Incubator "Colombian international political economy," Universidad del Rosario. Assistant researcher of the Research Incubator "Colombian Migrations Abroad.” Email: laura.manriquel@urosario.edu.co

Received: July 25, 2018; reviewed: August 25, 2018; accepted: August 27, 2018 


\section{Introducción}

Se busca describir el estado actual de la dinámica migratoria entre Colombia y Panamá y tratar dos temas: la migración regular y la migración ilegal. La regular, definida como "aquella migración que se hace a través de canales regulares y legales", es de especial interés, ya que Panamá es uno de los principales destinos migratorios para los colombianos, lo cual exige una revisión de los factores que la moldean y permiten.

Por otro lado, dado que la migración laboral o económica por canales legales no es la única entre Colombia y Panamá, es necesario indagar en la migración ilegal, entendida como "aquella migración que se hace de forma clandestina, al margen de las normas del Estado de envío, tránsito o recepción". ${ }^{2}$ Se utiliza el término migración ilegal porque "su uso se ha restringido a los fenómenos de tráfico ilícito de migrantes y trata de personas” ${ }^{3}$ y el fenómeno del tráfico ilícito de migrantes será estudiado en este artículo. Otras actividades delictivas que afectan la zona fronteriza colombo-panameña como el narcotráfico, tráfico ilícito de armas y el contrabando serán revisadas por su incidencia en la dinámica de la migración ilegal y no como sucesos aislados.

\section{Panamá como destino migratorio para los colombianos: factores de atracción y economía panameña}

Panamá se ha consolidado como uno de los principales destinos migratorios para los colombianos, luego de las primeras olas migratorias hacia el exterior durante las décadas del sesenta y del setenta, cuyos destinos principales eran Venezuela y Estados Unidos. Esta dinámica ha ido cambiando los destinos sur-norte, con una creciente migración sur-sur, por la que Panamá, junto con Argentina y Chile, se consolida como uno de los rumbos regionales para los migrantes colombianos. ${ }^{4}$

Panamá ha sido un destino migratorio de gran concurrencia durante el siglo XX. Dada su ubicación geográfica, se ha caracterizado por ser un país de tránsito naval y, más recientemente, aéreo. La gran incidencia que tuvieron las poblaciones

\footnotetext{
Organización Internacional para las Migraciones [OIM], Glosario sobre migración (Ginebra: Autor, 2006), 41. OIM, Glosario sobre migración, 40

OIM, Glosario sobre migración, 40.

Departamento Nacional de Planeación [DNP], Dinámicas y flujos migratorios Colombia-Panamá: estado actual y perspectivas futuras (Bogotá: Autor, 2016), 19.
} 
inmigrantes determinaron los procesos de poblamiento del país: "[... entre 1896 y 1930, la población total aumentó de 316.000 a 512.000 [por lo que la inmigración] enriqueció las habilidades del país, pero obstaculizó el proceso de construcción de una nación". 5

Entre las poblaciones migrantes se destacaba la presencia de estadounidenses, antillanos, jamaiquinos, libaneses, chinos, británicos, franceses, italianos, españoles y alemanes, grupos que basaban su llegada al país en las actividades económicas de la zona del canal, bajo control estadounidense desde la firma del Acuerdo Taft de 1904. Estas condiciones derivaron en la constitución de una multiplicidad de políticas reactivas y luchas sociales ante el fenómeno - las cuales buscaban obtener un dominio político y económico autónomo frente a una condición de influencia transversal de Estados Unidos-, tales como la proliferación de sindicatos y federaciones de trabajadores en el decenio de 1920, el avance político de la Acción Comunal como fuerza nacionalista y la promulgación de la Constitución Nacional de 1941 — que fue derogada por la Constitución de 1946 — bajo la presidencia de Arnulfo Arias Madrid (1940-1941), entre otros acontecimientos que reflejaban la situación de Panamá respecto a la influencia estadounidense y el ascenso meteórico de las migraciones.

Fue con el golpe de Estado de 1968, perpetrado por el comandante de la Guardia Nacional, el general Omar Torrijos, que inició la revolución panameña materializada con la Constitución de 1972. Durante este período, además de lograr la negociación del acuerdo de 1977 con Estados Unidos, que declaró plena soberanía de Panamá sobre la zona del canal, se desarrolló un proceso de diversificación económica mediante el establecimiento de un sistema bancario extraterritorial; esa iniciativa "incrementó las inversiones de capital, el empleo administrativo y la construcción [...]"6 y que potenció a Panamá como un "exportador de servicios internacionales en vez de limitarse a ser una ruta marítima". ${ }^{7}$

Como resultado de estos avances hubo un gran endeudamiento del Estado panameño y se dio continuidad a las directrices esbozadas por Torrijos hasta su muerte, en 1981. Ello ocasionó una crisis política conducente al ascenso del general Manuel Antonio Noriega en 1983, que propició un escenario de dificultad económica tras

Michael Conniff, "Panamá desde 1903" en Historia de América Latina, vol. 15. América Central desde 1930, ed. Leslie Bethell (Madrid: Crítica, 1997), 248.

6 Conniff, "Panamá desde 1903", 277.

7 Conniff, "Panamá desde 1903", 278. 
el bloqueo que impuso Estados Unidos a Panamá por la proximidad de este militar con redes de narcotráfico:

[...] los Estados Unidos embargaron activos panameños, se negaron a efectuar los pagos correspondientes al canal y rehusaron suministrar billetes de dólar en los que se basaba la economía panameña, [además de causar] el cierre inmediato del estratégico sistema bancario y precipitó una grave crisis. ${ }^{8}$

Tras el desconocimiento de los resultados de las elecciones presidenciales de 1989, Estados Unidos intervino militarmente el país mediante la operación Causa justa y depuso a Noriega luego de su refugio en la embajada vaticana.

Después de la década del ochenta, la emigración panameña no ha sido de la magnitud de otros países de la región como El Salvador, Guatemala y Honduras; al contrario, Panamá ha sido un destino migratorio de carácter extrarregional —migraciones de países no centroamericanos-.

Según los registros del Instituto Nacional de Estadística y Censos (INEC) (Tabla 1), la población de colombianos en Panamá no ha dejado de crecer en los últimos veinte años, la cual en 2010 conformaba el primer grupo de inmigrantes extrarregionales en Panamá con una cifra de 41.855 personas; ello ha representado un incremento de 98,7 \% en un lapso de diez años, en comparación con los registros de 2000. Además, según Naciones Unidas, ${ }^{9}$ la cifra de colombianos en Panamá incluso ascendería hasta 57.051 personas, lo cual denota una preservación de la tendencia de crecimiento que se ha sostenido por más de treinta años.

Esta migración se posibilita por la cercanía geográfica y la facilidad para cruzar las fronteras y por los factores de atracción (pull factors) panameños. ${ }^{10}$ Las razones de que Panamá hubiera crecido como un destino de migración obedecen a una multiplicidad de elementos, entre los que se destaca la nacionalización del canal en 1999, el mejoramiento del comercio internacional gracias a él y el restablecimiento de un mercado internacional de provisión de servicios. A pesar de la ralentización de

Conniff, "Panamá desde 1903", 280.

Organización de Naciones Unidas [ONU], "Total International Migrant Stock Report by Country of Origin and Destination, 1990-2017”, https://goo.gl/2tWzpi (acceso julio 6, 2018).

10 Guillermo Acuña, coord., Flujos migratorios laborales intrarregionales: situación actual, retos y oportunidades en Centroamérica y República Dominicana (San José: OIM, OIT, MTSS, CECC SICA, OCLAD, Red de Observatorios del Mercado Laboral, AECID, 2011), 29. 
la economía panameña en 2009, luego de 2011 el país se recuperó y fue uno de los países latinoamericanos con mayor desarrollo económico. ${ }^{11}$

Tabla 1. Población extranjera en Panamá por nacionalidad, 1990-2017

\begin{tabular}{|c|c|c|c|c|c|c|c|}
\hline Censo 1990 & 61.400 & Censo 2000 & 82.097 & Censo 2010 & 148.779 & Est. 2017* & 190.728 \\
\hline Colombia & 13.644 & Colombia & 21.069 & Colombia & 41.885 & Colombia & 57.051 \\
\hline Taiwán & 6.754 & China & 9.093 & China & 13.910 & China & 19.273 \\
\hline Nicaragua & 4.447 & $\begin{array}{c}\text { República } \\
\text { Dominicana }\end{array}$ & 5.753 & Estados Unidos & 10.645 & Estados Unidos & 14.497 \\
\hline Costa Rica & 3.829 & $\begin{array}{c}\text { Estados } \\
\text { Unidos }\end{array}$ & 5.113 & Nicaragua & 9.798 & Nicaragua & 13.335 \\
\hline China & 3.244 & Nicaragua & 4.833 & Venezuela & 7.497 & Venezuela & 10.204 \\
\hline $\begin{array}{c}\text { Estados } \\
\text { Unidos }\end{array}$ & 3.242 & Costa Rica & 4.565 & $\begin{array}{c}\text { República } \\
\text { Dominicana }\end{array}$ & 6.141 & $\begin{array}{c}\text { República } \\
\text { Dominicana }\end{array}$ & 8.358 \\
\hline Cuba & 3.191 & Perú & 2.649 & Costa Rica & 5.888 & Costa Rica & 8.012 \\
\hline España & 2.448 & España & 2.468 & México & 3.665 & México & 4.989 \\
\hline El Salvador & 2.340 & México & 2.299 & India & 3.400 & India & 4.626 \\
\hline Perú & 1.740 & India & 2.056 & Perú & 3.256 & Perú & 4.429 \\
\hline
\end{tabular}

Fuente: elaboración propia con base en Comisión Económica para América Latina [Cepal], "Investigación de la migración internacional en Latinoamérica (Imila)", http://goo.gl/RkVkLf (acceso junio 25, 2018).

*Los datos para 2017 son una estimación de Organización de Naciones Unidas [ONU], "Total International Migrant Stock Report by Country of Origin and Destination, 1990-2017”, https://goo.gl/2tWzpi (acceso julio 6, 2018).

Los factores de atracción encontrados en Panamá pueden identificarse en los registros de Migración Colombia entre 2007 y 2015, en los que el número de flujos migratorios por concepto de actividades laborales ascendió de 16.802, en 2007 a 25.376, en 2015 (Gráfico 1). Además, las dos motivaciones principales de los colombianos para migrar a Panamá fueron residencia y trabajo. Estas tendencias muestran que Panamá es un destino en donde el migrante encuentra una mejor calidad de vida, lo cual puede relacionarse con el crecimiento económico y el índice de desarrollo humano del país.

Por otro lado, dado que otra de las motivaciones de los colombianos para migrar a Panamá es laboral, se entiende que los colombianos tienen un perfil profesional o una formación laboral valorada en Panamá o que este Estado ofrece oportunidades laborales. El perfil educativo del migrante colombiano ha cambiado: en 1980, la población con menos de seis años de educación representaba un 63,8 \%, mientras

11 DNP, Dinámicas y flujos migratorios Colombia-Panamá, 24. 
que en el año 2000 disminuyó a 38,7 \%; la población que tenía diez o más años de educación aumentó a un $45 \%{ }^{12}$

La cifra de colombianos económicamente activos asciende a 22.195 para 2010, cuya ocupación laboral se refleja en una mayor participación en actividades económicas de los sectores de transporte, almacenamiento y comunicaciones (4.484); comercio, restaurantes y hoteles (2.680); en la prestación de servicios sociales, comunales y personales (2.240); en la provisión de electricidad, gas y agua (1.724) y una creciente participación en otros rubros en los que el mercado laboral panameño ha tenido una mejora (Tablas 2 y 3 ).

Los desplazamientos de la migración laboral y de residencia aquí mencionada se hicieron casi en su totalidad en avión y solo un 3 \% hacia puertos marítimos. ${ }^{13}$ Señalar la forma de los desplazamientos es crucial, puesto que a partir de ella se puede inferir la capacidad económica del migrante colombiano y su disposición a hacerlos dentro de los marcos legales de ambos Estados. Esta caracterización es distinta a la del migrante irregular o del refugiado, estudiadas más adelante.

La economía dolarizada panameña es otro factor principal de atracción de migrantes, como un incentivo cambiario diferencial. Esta dinámica es de especial interés, puesto que Colombia, que tenía una población emigrante mayor a 3’378.354 de personas para 2005, ${ }^{14}$ está entre los diez países receptores de remesas de América Latina y el Caribe, cuyo máximo tope fue alcanzado en 2016 con la entrada de 228.7 millones de dólares percibidos desde Panamá (Gráfico 2). ${ }^{15}$

La dinámica económica también puede verse como un "imaginario común" que tienen los inversionistas y migrantes económicos y también indígenas, desplazados y personas con capacidades económicas limitadas. Se propone como imaginario porque la prometedora idea del crecimiento económico choca de frente con la realidad de una desigualdad presente en Panamá en las zonas fronterizas, un sistema administrativo deficiente y un sistema judicial, en varios casos, corrupto. ${ }^{16}$

\footnotetext{
DNP, Dinámicas y flujos migratorios Colombia-Panamá, 30.

DNP, Dinámicas y flujos migratorios Colombia-Panamá, 29.

14 Departamento Administrativo Nacional de Estadística [DANE], "Censo general 2005", https://www.dane. gov.co/index.php/estadisticas-por-tema/demografia-y-poblacion/censo-general-2005-1 (acceso junio 29, 2018)

15 Banco de la República, "Remesas", http://goo.gl/WLmq5b (acceso julio 17, 2018).

16 Kevin Sánchez Saavedra, "Migración y refugio en Panamá", Encuentro: revista académica de la Universidad Centroamericana 80, núm. 1 (2008): 99.
} 
Gráfico 1. Población colombiana por sexo, estado civil, condición de actividad e inactividad, 1990-2011

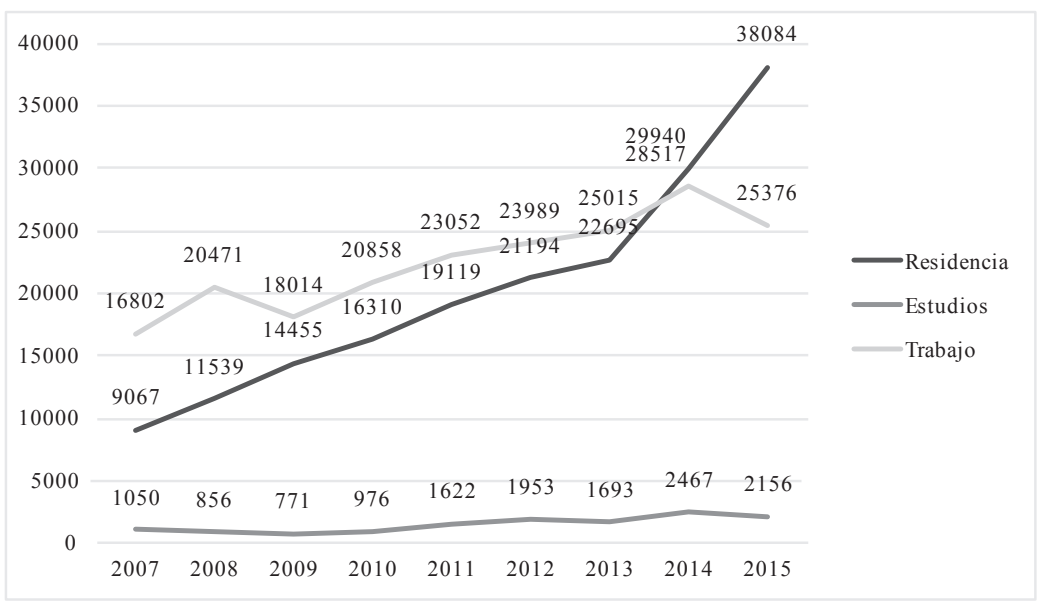

Fuente: elaboración propia con base en Cepal, "Investigación de la migración internacional en Latinoamérica (Imila)".

Gráfico 2. Evolución de las remesas entrantes en Colombia provenientes de Panamá, 2005-2016

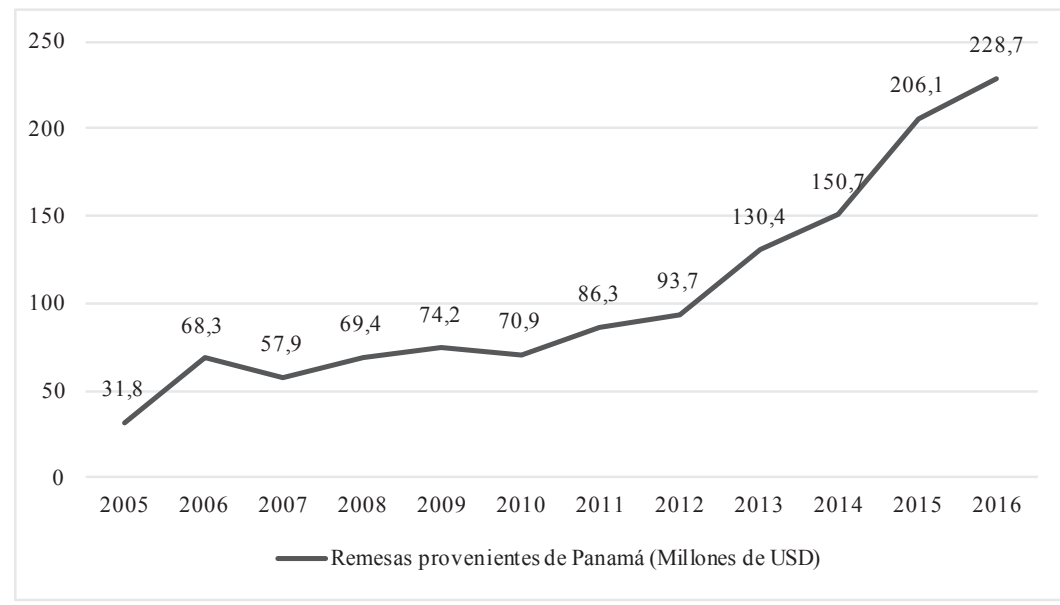

Fuente: elaboración propia con base en Banco de la República, "Remesas", http://goo.gl/WLmq5b (acceso julio 17, 2018). 
Tabla 2. Población colombiana por sexo, estado civil, condición de actividad e inactividad, 1990-2011

\begin{tabular}{|c|c|c|c|c|c|c|c|c|c|}
\hline \multirow{2}{*}{ Colombia } & & \multirow{2}{*}{\multicolumn{2}{|c|}{$\begin{array}{c}1990 \\
13.644\end{array}$}} & & \multirow{2}{*}{\multicolumn{2}{|c|}{\begin{tabular}{|l}
2000 \\
21.069
\end{tabular}}} & & \multirow{2}{*}{\multicolumn{2}{|c|}{$\begin{array}{l}2010 \\
41.885\end{array}$}} \\
\hline & & & & & & & & & \\
\hline \multirow{2}{*}{ Grupo de sexos } & & Hombres & Mujeres & & Hombres & Mujeres & & Hombres & Mujeres \\
\hline & & 6.786 & 6.858 & & 10.376 & 10.693 & & 19.012 & 22.783 \\
\hline $\begin{array}{c}\text { Estados Civil } \\
(+)\end{array}$ & Total & Hombres & Mujeres & Total & Hombres & Mujeres & Total & Hombres & Mujeres \\
\hline Solteros & 2.612 & 1.336 & 1.276 & 4.571 & 2.384 & 2.187 & 10.075 & 4.929 & 5.146 \\
\hline Casados y unidos & 7.652 & 4.015 & 3.637 & 11.127 & 5.836 & 5.291 & 22.650 & 10.709 & 11.941 \\
\hline Otros & 2.420 & 965 & 1.455 & 3.410 & 1.164 & 2.246 & 5.572 & 1.582 & 3.990 \\
\hline $\begin{array}{c}\text { Condición de } \\
\text { Actividad }(+15)\end{array}$ & Total & Hombres & Mujeres & Total & Hombres & Mujeres & Total & Hombres & Mujeres \\
\hline Activos & 6.318 & 4.454 & 1.864 & 10.483 & 6.464 & 4.019 & 22.195 & 11.967 & 10.228 \\
\hline Inactivos & 6.245 & 1.801 & 4.444 & 7.385 & 2.131 & 5.254 & 13.632 & 3.970 & 9.662 \\
\hline Inactivos & Total & Hombres & Mujeres & Total & Hombres & Mujeres & Total & Hombres & Mujeres \\
\hline Estudiante & 976 & 484 & 492 & 1.349 & 656 & 693 & 4.273 & 1.968 & 2.305 \\
\hline Ama de casa & 3.165 & 0 & 3.165 & 3.566 & 85 & 3.481 & 5.915 & 142 & 5.773 \\
\hline $\begin{array}{l}\text { Jubilado o } \\
\text { pensionado }\end{array}$ & 969 & 672 & 297 & 1.099 & 621 & 478 & 1.269 & 598 & 671 \\
\hline Otros & 1.135 & 645 & 490 & 1.371 & 769 & 602 & 2.175 & 1.262 & 913 \\
\hline
\end{tabular}

Fuente: elaboración propia con base en Cepal, "Investigación de la migración internacional en Latinoamérica (Imila)".

Tabla 3. Población colombiana en Panamá económicamente activa mayor de 15 años por actividad laboral, 1990-2010

\begin{tabular}{|c|c|c|c|c|c|c|c|c|c|}
\hline Colombia & & \multicolumn{2}{|c|}{1990} & & \multicolumn{2}{c|}{2000} & & \multicolumn{2}{|c|}{2010} \\
\hline $\begin{array}{c}\text { Actividad } \\
\text { Laboral (+15) }\end{array}$ & Total & Hombres & Mujeres & Total & Hombres & Mujeres & Total & Hombres & Mujeres \\
\hline $\begin{array}{c}\text { Agricultura, } \\
\text { caza, pesca y } \\
\text { silvicultura }\end{array}$ & 1.832 & 1.689 & 143 & 1.694 & 1.573 & 121 & 1.220 & 1.101 & 119 \\
\hline Minas y canteras & 37 & 36 & 1 & 34 & 29 & 5 & 40 & 36 & 4 \\
\hline $\begin{array}{c}\text { Industrias } \\
\text { manufactureras }\end{array}$ & 653 & 455 & 198 & 1.047 & 688 & 359 & 489 & 340 & 149 \\
\hline $\begin{array}{c}\text { Electricidad, gas } \\
\text { y agua }\end{array}$ & 21 & 19 & 2 & 23 & 22 & 1 & 1.724 & 1.198 & 526 \\
\hline Construcción & 222 & 218 & 4 & 794 & 773 & 21 & 134 & 2.451 & 41 \\
\hline $\begin{array}{c}\text { Comercio, restau- } \\
\text { rantes y hoteles }\end{array}$ & 1.507 & 997 & 510 & 2.973 & 1.718 & 1.255 & 2.680 & 93 & 229 \\
\hline $\begin{array}{c}\text { Transporte, } \\
\text { almacenamiento } \\
\text { y comunicaciones }\end{array}$ & 304 & 264 & 40 & 494 & 402 & 92 & 4.484 & 2.676 & 1.808 \\
\hline
\end{tabular}




\begin{tabular}{|c|c|c|c|c|c|c|c|c|c|}
\hline $\begin{array}{c}\text { Establecimientos } \\
\text { financieros, segu- } \\
\text { ros y servicios }\end{array}$ & 227 & 152 & 75 & 692 & 417 & 275 & - & - & - \\
\hline $\begin{array}{c}\text { Servicios comu- } \\
\text { nales, sociales y } \\
\text { personales }\end{array}$ & 1,117 & 372 & 745 & 2.215 & 575 & 1.640 & 2.240 & 896 & 1.344 \\
\hline $\begin{array}{c}\text { Servicio } \\
\text { doméstico }\end{array}$ & 318 & 217 & 217 & 297 & 203 & 94 & 344 & 175 & 169 \\
\hline
\end{tabular}

Fuente: elaboración propia con base en Cepal, "Investigación de la migración internacional en Latinoamérica (Imila)".

\section{Dinámica social y legal enfrentada por los migrantes colombianos en Panamá y la zona de frontera}

Panamá es el tercer país latinoamericano con mayor número de migrantes colombianos, lo cual ha sido una dinámica permanente y creciente durante las últimas dos décadas. ${ }^{17}$ De acuerdo con información del INEC compilada por el Proyecto Imila de la Cepal, ${ }^{18}$ la población colombiana en Panamá se ha distribuido en varias provincias, aunque predomina la tendencia a asentarse en las de Panamá (31.761 habitantes) y Colón (4.044), que albergan un 85 \% de la población colombiana. También hay poblaciones de tamaño relevante en Darién, Coclé y Chiriquí, con una densidad poblacional considerable (Mapa 1). La información de los censos es criticada, pues muchos colombianos que migran y se quedan en territorio panameño de forma irregular tienen miedo a ser deportados y afirman que son panameños. ${ }^{19}$

El crecimiento sostenido de colombianos en Panamá ha sido percibido como una dinámica no deseada, hasta el punto de ser estigmatizados como delincuentes, narcotraficantes, guerrilleros, etc. Se ha instaurado un sentimiento nacionalista de "Panamá para los panameños", dado el incremento de la inmigración y la competencia laboral que atribuyen a ese fenómeno. También se culpa a la migración colombiana de causar un aumento en la inseguridad, ya que los colombianos representan la mayor población de extranjeros en Panamá y se refuerzan estereotipos negativos de nuestros connacionales. ${ }^{20}$ Ello incentiva a resaltar el "aumento de la xenofobia y discriminación hacia los migrantes y refugiados colombianos en Panamá”. ${ }^{21}$

17 DNP, Dinámicas y flujos migratorios Colombia-Panamá, 27.

18 Comisión Económica para América Latina [Cepal], "Investigación de la migración internacional en Latinoamérica (Imila)", http://goo.gl/RkVkLf (acceso junio 25, 2018).

19 Acuña, Flujos migratorios laborales intrarregionales, 91.

20 "Diputada panameña llamó 'escoria' a inmigrantes colombianos", Noticiascaracol.com, 24 de febrero de 2015, https://goo.gl/jQtyFp (acceso mayo 25, 2018).

21 Sánchez Saavedra, "Migración y refugio en Panamá", 101. 
Este suceso fue combatido por una política denominada "crisol de razas", que estuvo en vigor entre 2010 y 2014 y propuso "ofrecer un estatus legal a los trabajadores indocumentados, mayormente colombianos, que aportan al crecimiento de Panamá". 22 Por ella "se legalizaron en Panamá a 57.652 extranjeros, de los cuales 27.541 eran colombianos". ${ }^{23}$ Esta política fue suspendida en 2014 y derogada por el actual gobierno de Juan Carlos Varela. Más adelante "se impusieron condiciones más estrictas para solicitar la residencia en Panamá, las cuales no eran exigidas anteriormente". ${ }^{24}$

Panamá, Ecuador y Venezuela son los países que más solicitudes de asilo han recibido por parte de colombianos (Tabla 4). Para 2010, según la Acnur, se recibieron 537 solicitudes de asilo, se encontraban 1.299 personas en condición de refugiados y otras 15.000 en condiciones similares a la de refugiado..$^{25}$

El conflicto armado interno en Colombia es uno de los factores de expulsión de colombianos que buscan protección en otros territorios, en apelación a la figura del refugio para su correspondiente amparo. En la década del noventa, como respuesta al incremento de migrantes y personas en situación de refugio de nacionalidad colombiana que llegaron a Panamá, se creó por decreto ejecutivo el estatus de protegidos humanitarios temporales, que fue concedido a la población migrante en frontera. Los criterios de durabilidad y aplicabilidad son poco claros y limita el desplazamiento en territorio a las personas a las que se les otorga.

La población en situación de refugio enfrenta un largo proceso administrativo para la solicitud. A aquellas personas que consiguen el estatus de refugiados no se les concede automáticamente un permiso de trabajo, lo cual se convierte en un trámite cuyo diligenciamiento no es rápido. Además, estas personas — que de por sí están en una situación de alta vulnerabilidad - deben afrontar problemas para acceder a salud, educación y vivienda. ${ }^{26}$ Hoy sigue siendo problemático para las poblaciones migrantes en frontera obtener el estatus de refugiado en Panamá, debido al inadecuado funcionamiento de las instituciones del país. ${ }^{27}$

22 Luis Guillermo Restrepo, "Crisol de razas", El País, 1 de marzo de 2015, https://goo.gl/NSVqQx (acceso mayo 25, 2018).

23 José Arcia, "Residentes en Panamá, cerca de los 5 millones", La Estrella de Panamá, Secc. Nacional, 9 de junio de 2016, https://goo.gl/UrcKGC (acceso mayo 25, 2018).

24 "Panamá decreta nuevo proceso de regularización migratoria", El Espectador, 3 de junio de 2016, https:// goo.gl/WUi33s (acceso mayo 25, 2018).

25 DNP, Dinámicas y flujos migratorios Colombia-Panamá, 33.

26 Sánchez Saavedra, "Migración y refugio en Panamá", 104-105.

27 "La frontera colombo-panameña: migración ilegal y drama de desplazados", Caracol Radio, 7 de febrero de 2017, https://goo.gl/pf8tdn (acceso mayo 25, 2018). 
Por otra parte, aquellas personas a quienes se les rechaza la solicitud de refugio pasan a ser catalogadas como migrantes económicos, lo cual desconoce y problematiza aún más su vulnerabilidad, ya que pone al descubierto su identidad ante las autoridades y los desprovee de la protección necesaria que determina su salvaguarda. ${ }^{28}$ En Panamá, el tema migratorio ha sido manejado como un asunto de seguridad nacional, en el que "no ha primado el respeto por las garantías que deben ofrecérseles a las personas en dicha vulnerabilidad y no se ha dado una respuesta comprensiva entre ambos Estados para proteger a los migrantes en esta zona de frontera". ${ }^{29}$

Tabla 4. Países latinoamericanos con mayor número de refugiados colombianos (aproximado para 2016)

\begin{tabular}{|c|c|c|c|c|}
\hline País & Ecuador & Venezuela & Panamá & Costa Rica \\
\hline Colombia & 226.000 & 173.673 & 15.593 & 2.247 \\
\hline
\end{tabular}

Fuente: elaboración propia con base en ONU, "Total International Migrant Stock Report by Country of Origin and Destination, 1990-2017".

La frontera de 266 kilómetros de extensión entre Colombia y Panamá sigue siendo una zona de exclusión y abandono estatal, en donde se vio el impacto del desplazamiento forzado de grupos indígenas provocado por el enfrentamiento armado entre paramilitares, guerrilla y Ejército colombiano ${ }^{30}$ y por la economía de narcóticos en la subregión del Urabá antioqueño. ${ }^{31}$ Esta lógica ha estado presente durante varias décadas y aún se identifica la presencia de afrodescendientes e indígenas colombianos en los municipios fronterizos del Chocó. ${ }^{32}$

La frontera colombo-panameña tiene una importancia ancestral para los grupos indígenas. Se sabe que el desplazamiento de los grupos indígenas emberá y wounaan está asociado con una práctica migratoria cultural, derivada de su sistema de producción. Por otro lado, aunque es una razón importante, no puede señalarse aisladamente al conflicto armado como causa de la migración transfronteriza indígena, sino que este fenómeno debe relacionarse con "alta exclusión social

28 Sánchez Saavedra, "Migración y refugio en Panamá", 104-105.

29 Servicio Jesuita a Refugiados, "Panamá: la migración forzada desde la opinión pública". https://goo.gl/ GoJWVU (acceso mayo 25, 2018).

30 Acela Pujol, "La frontera colombo-panameña: una frontera selvática, cerrada al progreso pero abierta a las migraciones más disímiles”, Estudios Fronterizos 40, núm. 4 (1997): 91

31 Organización Internacional para las Migraciones [OIM], Estudio investigativo para la descripción y análisis de la situación de la migración y trata de personas en la zona fronteriza colombo-panameña (Bogotá: Autor, 2007), 8-9.

32 DNP, Dinámicas y flujos migratorios Colombia-Panamá, 47. 
y empobrecimiento en las que se encuentran dichas comunidades indígenas". ${ }^{33}$ Esta consideración debe hacerse puesto que Chocó, zona de donde provienen los grupos indígenas mencionados, ha sido y sigue siendo una zona marginada del desarrollo, cuyos municipios que colindan con Panamá (Riosucio, Unguía, Juradó y Acandí) presentan un alto porcentaje de necesidades básicas insatisfechas: entre un 49 y un $82 \% .{ }^{34}$

\section{Tierra de nadie: migración ilegal por la zona fronteriza del Darién}

Para complementar el estudio del estado migratorio entre Colombia y Panamá, nuestros esfuerzos se dirigen ahora a revisar una dinámica pasada por alto en estudios como el del Departamento Nacional de Planeación de 2016 y es la de la migración ilegal. Como ya se señaló en las secciones anteriores, Panamá es un destino migratorio para los colombianos, lo cual hace que Colombia sea un país emisor. Esta caracterización no es la misma cuando se tratan los temas del tráfico ilícito de migrantes y la trata de personas puesto que "en las redes internacionales de crimen organizado, tanto Panamá como Colombia son países de tránsito". ${ }^{35}$

Puesto que el tráfico ilícito de migrantes y la trata de personas son dos elementos que se circunscriben en la migración ilegal, acerca de los cuales suelen hablar y explicar los medios de comunicación, es necesario contribuir al esfuerzo académico por la distinción conceptual entre ellos. En primer lugar, el tráfico ilícito de migrantes que se define en el Protocolo contra el tráfico ilícito de migrantes por tierra, mar y aire, firmado en el año 2000, ${ }^{36}$ complementa la Convención de Naciones Unidas contra el crimen organizado. Fue ratificado por Panamá el 18 de agosto de 2004. ${ }^{37}$ Aunque Colombia no lo ratificó, "este Estado responde a parámetros establecidos en él", ${ }^{38}$ como lo demuestra el director de Migración Colombia al señalar que las víctimas del tráfico ilícito de migrantes "no pueden ser judicializadas, por respeto a

33 Kevin Sánchez Saavedra, "Migración transfronteriza indígena en Darién, Panamá", Estudios Centroamericanos 699-700, núm. 3 (2007): 70.

34 DNP, Dinámicas y flujos migratorios Colombia-Panamá, 22.

35 Oficina de las Naciones Unidas contra la droga y el delito [UNODC], Dimensión del delito de tráfico de migrantes en Colombia: realidades institucionales, legales y judiciales (Bogotá: Autor, 2013), 17.

36 Organización de Naciones Unidas [ONU], Protocolo contra el tráfico ilícito de migrantes por tierra mar y aire (Nueva York, 12 de diciembre de 2000), art. 1.

37 Organización de Naciones Unidas [ONU], Protocolo para prevenir, suprimir y sancionar el tráfico de personas, especialmente mujeres y niños (Palermo, 15 de noviembre de 2000).

38 UNODC, Dimensión del delito de tráfico de migrantes en Colombia, 28. 
tratados internacionales y para no re-victimizarlas". ${ }^{39}$ En el mencionado Protocolo se define el tráfico ilícito de migrantes como "la facilitación de la entrada ilegal de una persona en un Estado Parte del cual, dicha persona no sea nacional o residente permanente con el fin de obtener, directa o indirectamente, un beneficio financiero u otro beneficio de orden material". ${ }^{40}$

Ya que Colombia no ratificó el Protocolo citado, para este Estado la definición de tráfico ilícito de migrantes consiste en:

[...] el que promueva, induzca, constriña, facilite, financie, colabore o de cualquier otra forma participe en la entrada o salida de personas del país, sin el cumplimiento de los requisitos legales, con el ánimo de lucrarse o cualquier otro provecho para sí u otra persona, incurrirá en prisión de noventa y seis (96) a ciento cuarenta y cuatro (144) meses, y una multa de sesenta y seis punto sesenta y seis (66.66) a ciento cincuenta (150) salarios mínimos legales mensuales vigentes al momento de la sentencia condenatoria. ${ }^{41}$

La trata de personas está definida en el Protocolo para prevenir, reprimir y sancionar la trata de personas, especialmente mujeres y niños, ratificado tanto por Colombia como por Panamá en el año 2004, así:

La captación, el transporte, el traslado, la acogida o la recepción de personas, recurriendo a la amenaza o al uso de la fuerza u otras formas de coacción, al rapto, al fraude, al engaño, al abuso de poder o de una situación de vulnerabilidad o a la concesión o recepción de pagos o beneficios para obtener el consentimiento de una persona que tenga autoridad sobre otra, con fines de explotación. Esa explotación incluirá, como mínimo, la explotación de la prostitución ajena u otras formas de explotación sexual, los trabajos o servicios forzados, la esclavitud o las prácticas análogas a la esclavitud, la servidumbre o la extracción de órganos. ${ }^{42}$

Al comparar la definición de ambos fenómenos, el tráfico ilícito de migrantes no incluye ejercer coacción sobre la persona, por lo que puede entenderse que hay

39 Unidad Investigativa, "Así funciona la red que mueve 20 mil inmigrantes ilegales por Colombia", El Tiempo, 27 de septiembre de 2015. https://goo.gl/tZQ2AA (acceso mayo 25, 2018).

40 Organización de Naciones Unidas [ONU], Protocolo contra el tráfico ilícito de migrantes por tierra, mar y aire (Nueva York, 12 de diciembre de 2000), art. 1.

41 República de Colombia, Código Penal (Bogotá: Legis, 2000), art. 188.

42 ONU, Protocolo para prevenir, suprimir y sancionar el tráfico de personas, especialmente mujeres y niños, art. 3. 
cierto consentimiento del migrante irregular. Pero, al hacer una revisión de ambos términos, la línea que separa ambos fenómenos es muy delgada, dado que existen prácticas como usar a los migrantes a manera de correos humanos de droga o la continua exigencia por parte de los traficantes a sus víctimas de dinero para completar tramos. La legislación colombiana, por su parte, contempla al migrante irregular como "víctima"; así, aunque haya consentimiento, no se exonera de responsabilidad penal al traficante. ${ }^{43}$

Asegura Christian Krüger, director de Migración Colombia, que el "tráfico de personas se ha convertido en el tercer negocio ilícito más lucrativo; el primero sigue siendo el narcotráfico; el segundo, el tráfico de armas y el tercero, tráfico de migrantes". ${ }^{44}$ La frontera colombo-panameña fue la zona de mayor actividad de tráfico ilícito de migrantes en el período enero-septiembre de $2012 .{ }^{45}$ Para profundizar en el tema, es necesario caracterizar la zona de frontera para explicar los factores que han contribuido para que allí puedan ejecutarse actividades irregulares. Asimismo, es preciso identificar las rutas internacionales de tráfico de migrantes que operan en el Darién, señalar las respuestas estatales ante este fenómeno y contribuir con sugerencias a la toma de decisiones para mejorar la situación transfronteriza.

\section{Geografía de la frontera y rutas de tránsito}

Tanto Colombia como Panamá se encuentran "enclavadas en una zona de transición entre el norte y el sur del continente americano, conforman un nodo central en la consolidación de rutas de múltiples tráficos ilegales transnacionales". ${ }^{46}$ La geografía que caracteriza la zona fronteriza ha posibilitado la consolidación de varias dinámicas, legales e ilegales.

Los departamentos de Chocó y Antioquia, en Colombia, la ciudad de Puerto Obaldía en Panamá y el Darién, compartido por los dos Estados, son zonas que tienen salida al mar, lo cual ha facilitado la migración marítima. ${ }^{47}$ En ambos lados de la frontera se presentan preocupantes indicadores sociales: en Puerto Obaldía — en donde cerca de un 90 \% de la población es colombiana- existen altos índices de necesidades

43 UNODC, Dimensión del delito de tráfico de migrantes en Colombia, 243.

44 "Frontera entre Colombia y Panamá no estará cerrada sino más controlada: Migración", RCN Radio, 10 de mayo de 2016, https://goo.gl/Pe4Gtz (acceso mayo 25, 2018).

45 UNODC, Dimensión del delito de tráfico de migrantes en Colombia, 17.

46 Mauricio Palma y Farid Badrán, "Crimen transnacional organizado y utilitarismo sociológico: evidencia desde el tráfico de personas en Colombia", Oasis, núm. 25 (2017): 85.

47 OIM, Estudio investigativo para la descripción y análisis de la situación de la migración y trata de personas, 6. 
básicas insatisfechas. ${ }^{48}$ Como ya se mencionó, el departamento de Chocó presenta precaria calidad de vida, puesto que las necesidades básicas insatisfechas son muy altas. ${ }^{49}$ Por otro lado, como otras fronteras colombianas, en Chocó "la ausencia del Estado ha posibilitado la presencia y acción de grupos al margen de la ley en este territorio" ${ }^{50}$ que se lucran de diversas actividades como narcotráfico, tráfico ilegal de armas, contrabando, tráfico ilícito de migrantes, trata de personas, minería ilegal transfronteriza, entre otros. ${ }^{51}$

Como relatan migrantes extrarregionales que atraviesan la selva del Darién, el tramo entre Colombia y Panamá puede ser el más peligroso y arduo de todo el recorrido. Las rutas que usan algunas personas para desplazarse en Asia, África y Suramérica son variadas y se conectan con Colombia por tierra, mar y aire para recorrer este país por distintos medios (Mapas 2 y 3). En 2014, autoridades panameñas encontraron que alrededor de 6.326 migrantes llegaron a territorio panameño en lanchas; en los primeros tres meses de 2015 ya habían detectado a cerca de 3.800 migrantes en ruta, de los cuales 1.000 fueron encontrados en la jungla. ${ }^{52}$ Solo entre el 25 y el 30 de marzo del mismo año, la Armada colombiana detectó en la región 721 migrantes irregulares de Pakistán, Kazajstán, Somalia, Haití, Nepal, Senegal y Cuba. ${ }^{53}$

En Colombia, las cifras de migrantes irregulares no han disminuido. En 2014 "se encontraron alrededor de 2.100 migrantes irregulares en el territorio colombiano, mientras que en el 2016 la cifra aumentó a 9.377". ${ }^{4}$ Este fenómeno se explica principalmente por la llegada masiva de cubanos al territorio colombiano que buscaban atravesar Panamá y otros Estados centroamericanos, pues el anuncio de la pacificación de las relaciones entre Cuba y Estados Unidos generó cierta incertidumbre frente al futuro de los beneficios legales de los que gozan los cubanos al llegar a ese país. ${ }^{55}$

4 OIM, Estudio investigativo para la descripción y análisis de la situación de la migración y trata de personas, 11.

49 DNP, Dinámicas y flujos migratorios Colombia-Panamá, 85.

50 Palma y Badrán, "Crimen transnacional organizado y utilitarismo sociológico", 86.

51 Servicio Jesuita a Refugiados, "Panamá: la migración forzada desde la opinión pública".

52 Sara Schaefer, "A Dark, Deadly Path to the US. - Migrants from around the World Brave the Vipers, Bats and Bandits of Panama's Darien Gap to Reach America", Wall Street Journal, 29 de mayo de 2015, https:// goo.gl/qTxXQi (acceso mayo 25, 2018).

53 Jim Wyss, "Cuban Migrants Face Dangerous, Grueling Jungle Trip as Panama Clamps Down", Miami Herald, 9 de mayo de 2016, https://goo.gl/ltLnY6 (acceso mayo 25, 2018).

54 "Así opera la mafia del tráfico de migrantes en Colombia", El País, 7 de agosto de 2016, https://goo.gl/ TwEZgo (acceso mayo 25, 2018)

55 Melina Ocampo González y Sebastián Arboleda, "Colombia y los flujos mixtos de migrantes en el derecho internacional de los refugiados”, Opinión jurídica 15, núm. 30 (2016): 105. 
Los peligros en la selva del Darién pueden impedir que los migrantes irregulares lleguen a Puerto Obaldía. El tapón del Darién está compuesto por una selva húmeda, cálida y tupida habitada por animales salvajes e insectos que contagian enfermedades, en donde muchas veces quien intenta atravesar la selva puede perderse por varios días. El agua disponible no es limpia y provoca enfermedades gastrointestinales severas. ${ }^{56}$

Las rutas marítimas más usadas parten desde Turbo hacia Panamá. Este tramo se recorre en lanchas que no cuentan con seguridad y zarpan de noche, expuestas a los riesgos de la marea alta. Además, en algunos casos a las personas no se les entregan chalecos salvavidas. ${ }^{57}$

El tráfico de migrantes no es una actividad criminal aislada de otras como el narcotráfico o el contrabando y es mucho más cercana a la trata de personas, dada su naturaleza clandestina e ilegal.

El control de las rutas territoriales y marítimas para la operación de otros tráficos influye de manera directa o indirecta, ya que puede utilizarse a los migrantes como correos humanos de drogas y también pueden encontrarse grupos delictivos operando sobre las mismas rutas, por ejemplo, el Cartel del Golfo y las FARC sobre el Urabá antioqueño.$^{58}$ Las FARC cobran por guiar a los migrantes irregulares para atravesar el tramo de Chocó y la selva del Darién para llegar a Panamá. El Clan Úsuga ha estado involucrado en la extorsión de migrantes irregulares, al cobrarles una vacuna para permitir su paso o el uso de lanchas en Turbo o en el río Atrato. ${ }^{59}$ Algunos migrantes han tenido que "pagar a 'Los Urabeños' 700 dólares por el transporte en lancha". ${ }^{60}$

El tráfico ilícito de migrantes requiere articulación internacional y nacional entre quienes lo ejercen; por eso, en torno a él surgen beneficios a terceros. Servicios como hospedaje y alimentación, entre otros, por parte de terceros contribuyen a

56 "Panama's Perilous Jungle Is a New Route for Migrants", Wall Street Journal, 29 de mayo de 2015, https:// goo.gl/fZ5v9o (acceso mayo 25, 2018).

57 Ocampo González y Arboleda, "Colombia y los flujos mixtos de migrantes", 104.

58 Palma y Badrán, "Crimen transnacional organizado y utilitarismo sociológico", 88.

59 Ocampo González y Arboleda, "Colombia y los flujos mixtos de migrantes", 104.

60 Schaefer, "A Dark, Deadly Path to the US". 
que esta actividad se mantenga, dados los réditos que genera. ${ }^{61}$ También surgen delitos conexos como la falsificación de documentos y visas. ${ }^{62}$

Por otro lado, la corrupción es un factor que posibilita y perpetúa actos al margen de la ley como el tráfico ilícito de migrantes: se pagan sobornos a autoridades colombianas por parte de los migrantes irregulares o de los traficantes para no ser entregados a Migración Colombia ${ }^{63}$ en Panamá, algunos miembros del Servicio Nacional de Migración forman parte del negocio de trata de personas, como se evidenció en la destitución de dos funcionarios de la institución. ${ }^{64}$

Por otra parte, la flexibilización en materia de exención de visados por Estados fronterizos con Colombia, como Ecuador, impacta en el tráfico ilícito de personas de manera notoria, como lo demuestran los casos de chinos, ${ }^{65}$ quienes aprovechan estas exenciones de visado para recorrer trayectos migratorios establecidos por redes de tráfico ilícito de migrantes que permitan una conexión con Estados Unidos o Canadá.

\section{Respuestas estatales frente a los desafíos migratorios en la frontera colombo-panameña}

Un fenómeno actual que refleja la ineficiente respuesta de ambos Estados es la problemática surgida por la presencia de un gran número de personas en el puerto de Turbo de nacionalidades variadas, como cubana o haitiana, en 2016, el cual evidencia la gran vulnerabilidad de esta región.

La situación suscitada en 2016, que derivó en el cierre temporal por el Gobierno panameño de la frontera con Colombia, demuestra que sigue habiendo una respuesta insuficiente de las autoridades estatales de Colombia y Panamá para enfrentar la migración transfronteriza desde una lógica de cooperación internacional, no solo de grupos indígenas, campesinos o desplazados por la violencia, sino también de personas de otras nacionalidades que cruzan la frontera para ingresar irregularmente a Estados Unidos u otros destinos. Como sostiene la Comisión Interamericana de

\footnotetext{
${ }_{61}$ Palma y Badrán, "Crimen transnacional organizado y utilitarismo sociológico", 89.

62 UNODC, Dimensión del delito de tráfico de migrantes en Colombia, 61.

63 Palma y Badrán, "Crimen transnacional organizado y utilitarismo sociológico", 89; Ocampo González y Arboleda, "Colombia y los flujos mixtos de migrantes", 99.

64 "Dos funcionarios de migración entre 10 imputados por trata en Panamá", Las Américas, 30 de enero de 2017, https://goo.gl/DXa8TQ (acceso mayo 25, 2018).

65 DNP, Dinámicas y flujos migratorios Colombia-Panamá, 82.
} 
Derechos Humanos (CIDH), la utilización de canales irregulares y de traficantes de personas para migrar demuestra la insuficiencia de los mecanismos legales que pueden tener estos migrantes en Colombia o Panamá. ${ }^{66}$

El cierre de fronteras es una respuesta ineficaz frente al crimen transnacional, pues dado el elevado número de migrantes reposados en la zona de Urabá, esta situación puede volverse un caldo de cultivo para incrementar las actividades criminales de los traficantes de personas. ${ }^{67}$ Por otro lado, posibilita el aumento de violencia en la zona colombiana, al tener grupos criminales luchando por el control del negocio ilícito. ${ }^{68}$ Puede afirmarse que el cierre de frontera anunciado por Panamá en mayo de 2016 fue fomentado por razones políticas más que por razones prácticas. Aunque Colombia no es un lugar de destino para refugiados, por la ausencia de ayudas humanitarias y del otorgamiento de permisos de trabajo durante el trámite de solicitud, ${ }^{69}$ el cierre de frontera abre la posibilidad de un repliegue de migrantes, frente a lo cual "podría avecinarse una crisis humanitaria, puesto que no se tienen los recursos nacionales para proveer resguardo de emergencia". ${ }^{70}$

La cooperación binacional entre Colombia y Panamá se ha adelantado para fortalecer la presencia estatal en la frontera por medio de control militar, vigilancia continua y operaciones aéreas conjuntas para combatir las actividades delictivas transfronterizas. Instituciones como el Servicio Jesuita a Refugiados han formulado una fuerte crítica a la ausencia de consideraciones frente a la perspectiva de la seguridad humana, dado que la situación de las comunidades indígenas y afrodescendientes, así como la vulnerabilidad de las víctimas del tráfico de migrantes no son abordadas adecuadamente. $^{71}$

Las respuestas estatales frente al fenómeno del tráfico ilícito de migrantes no han sido las mejores. Una de las estrategias implementadas por Migración Colombia al identificar migrantes irregulares consiste en otorgar un salvoconducto por cinco días para que estas personas regresen hasta la última frontera cruzada. Esta política

\footnotetext{
66 Comisión Interamericana de Derechos Humanos, CIDH expresa profunda preocupación por situación de migrantes en Colombia, cerca de la frontera de Panamá. Comunicado No. 112/16 (Washington, 8 de agosto de 2016).

67 Palma y Badrán, "Crimen transnacional organizado y utilitarismo sociológico", 87.

68 Mike LaSusa, "Panama's Colombia Border Closure Could Fuel Human Trafficking", Insight Crime, 10 de mayo de 2016, https://goo.gl/Q2vbKh (acceso mayo 25, 2018).

69 Ocampo González y Arboleda, "Colombia y los flujos mixtos de migrantes", 101.

70 Wyss, "Cuban Migrants Face Dangerous, Grueling Jungle Trip as Panama Clamps Down".

71 Servicio Jesuita a Refugiados, "Panamá: la migración forzada desde la opinión pública".
} 
no ha tenido los resultados esperados, ya que los migrantes irregulares siguen su ruta inicial hacia su destino principal, que suele ser Estados Unidos o Canadá. ${ }^{72}$

Además, no ha habido un establecimiento de centros de recepción y acogida de migrantes. ${ }^{73}$ Esta idea fue sugerida hace diez años por la Organización Internacional para las Migraciones tras su estudio de la trata de personas, pero no ha habido avances en la materia. ${ }^{74}$ En 2007 también había desconocimiento en las instituciones llamadas a identificar y manejar el fenómeno de la movilidad humana y combatir la trata de personas en Colombia y en Panamá. Las instituciones tienen conocimientos generales que no se traducen necesariamente en acciones conjuntas. ${ }^{75}$ Tampoco hay un canal seguro al que puedan acudir los migrantes irregulares por su condición de ilegalidad, por lo que el único referente de posible éxito de su trayecto está en manos del traficante. ${ }^{76}$ Para empeorar el panorama, percepciones como las del secretario de Gobierno de Turbo, Emélides Muñoz, acerca de que "darles comida a los migrantes cubanos irregulares se volvería un problema mayor, ya que aumentaría el número de personas que llegarían y se quedarían en Turbo" 77 demuestran que Colombia ofrece una respuesta a los desafíos migratorios desde la óptica de la seguridad nacional. ${ }^{78}$

2 Ocampo González y Arboleda, "Colombia y los flujos mixtos de migrantes", 96.

73 Palma y Badrán, "Crimen transnacional organizado y utilitarismo sociológico", 88.

74 Organización Internacional para las Migraciones [OIM], Estudio investigativo para la descripción y análisis de la situación de la migración y trata de personas en la zona fronteriza colombo-panameña (Bogotá: Autor, 2007).

75 OIM, Estudio investigativo para la descripción y análisis de la situación de la migración y trata de personas, 14.

76 Mauricio Palma, "Ascenso, proliferación, gestión y ¿control? Tráfico de migrantes a través de las fronteras de Colombia en Fronteras en Colombia como zonas estratégicas: análisis y perspectivas, ed. Andrés Molano-Rojas (Bogotá: Konrad Adenauer Stiftung, 2016), 102.

77 Alessandro Rampietti, "Migrants stranded in Colombia as route to US closed", Aljazeera, 7 de julio de 2016, https://goo.gl/ZGv6ro (acceso mayo 25, 2018).

78 Irene Cabrera, "Conflicto armado, criminalidad y violencia en la frontera colombo-panameña: elementos críticos para buscar una transición" en Fronteras en Colombia como zonas estratégicas: análisis y perspectivas, ed. Andrés Molano-Rojas (Bogotá: Konrad Adenauer Stiftung, 2016), 232. 
Mapa 1. Densidad poblacional de colombianos por provincia en Panamá

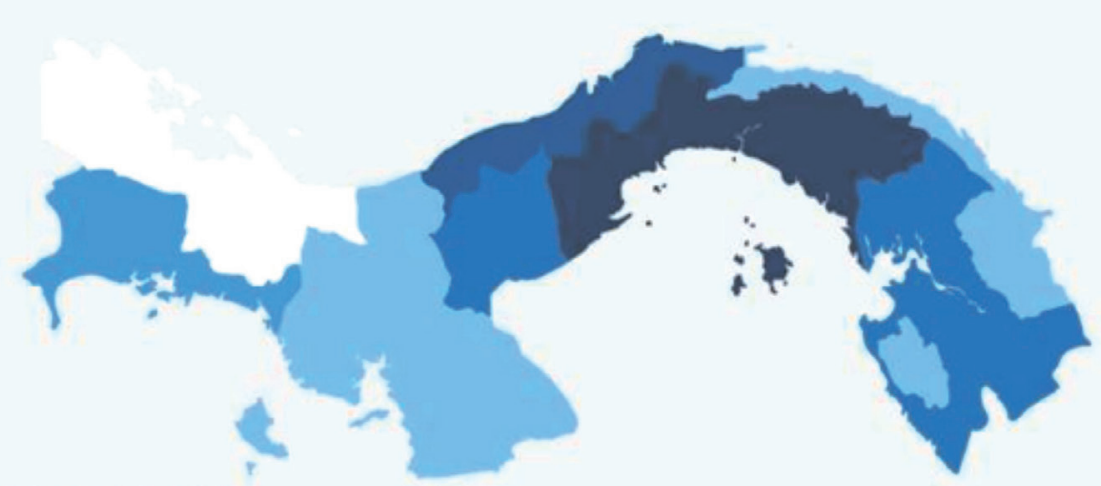

Panamá - 31.761

Colón - 4.044

Darién - 1.947

Coclé - 1.543

$\square+10.000$

Chiriquí - 770

Emberá - 393

$+4.000$

$+1.000$

$+500$

$+200$

Kuna Yala - 308

Fuente: elaboración propia con base en Comisión Económica para América Latina [Cepal], "Red de datos para áreas pequeñas por microcomputador (Redatam)", https://goo.gl/fGIU58 (acceso junio 25, 2018). 
Mapa 2. Rutas marítimas y aéreas del tráfico ilícito de migrantes que pasan por Colombia

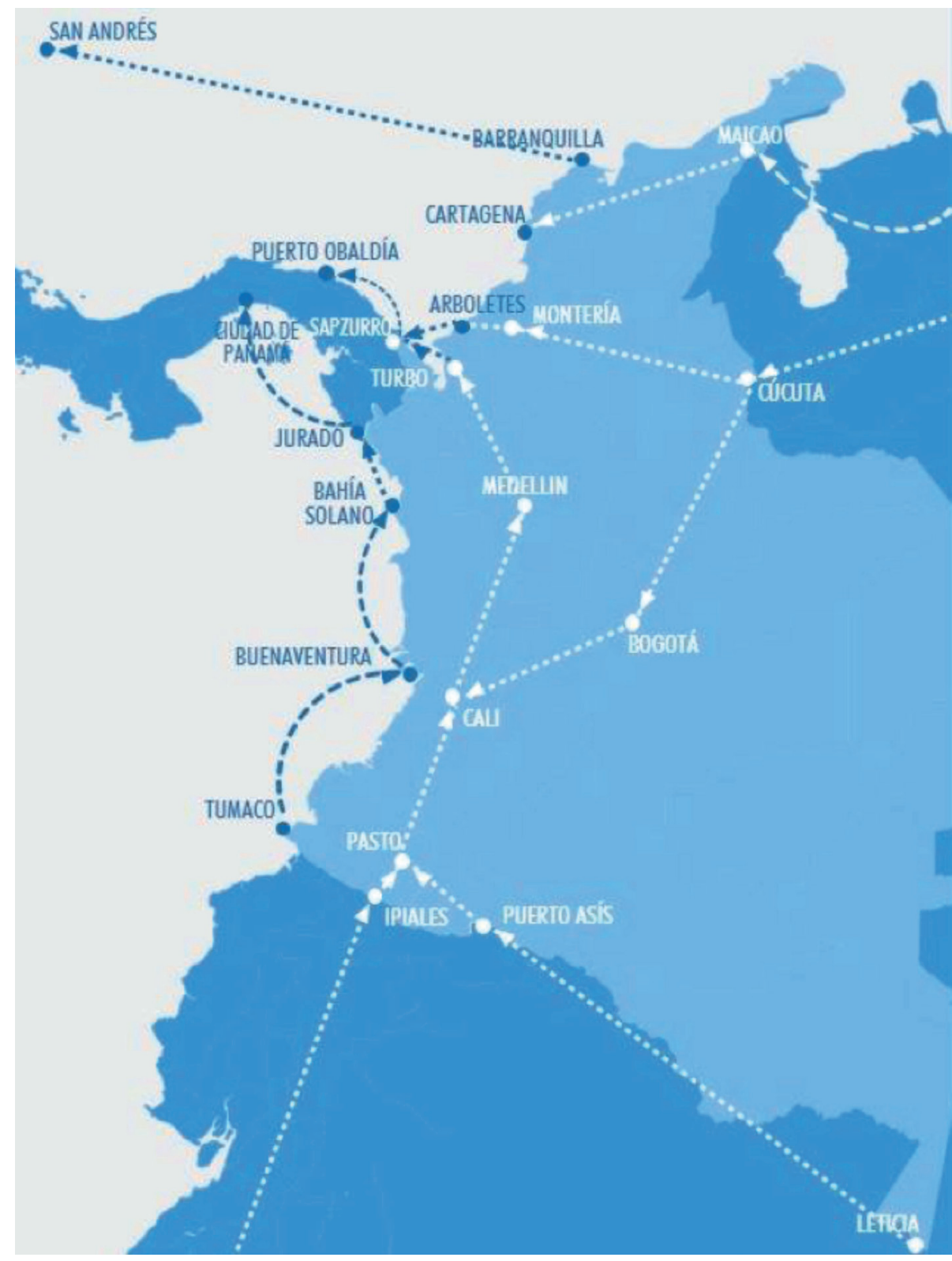

Fuente: elaboración propia con base en Melina Ocampo González y Sebastián Arboleda, "Colombia y los flujos mixtos de migrantes en el derecho internacional de los refugiados", Opinión jurídica 15, núm. 30 (2016): 102; Oficina de las Naciones Unidas contra la droga y el delito [UNODC], Dimensión del delito de tráfico de migrantes en Colombia: realidades institucionales, legales y judiciales (Bogotá: Autor, 2013), 23; "Estas son las rutas del tráfico de migrantes en Colombia", El País, 9 de noviembre de 2015. https://goo.gl/tzi7HX (acceso mayo 25, 2018). 
Mapa 3. Rutas aéreas, marítimas y terrestres de las redes internacionales de tráfico ilícito de migrantes que pasan por Colombia

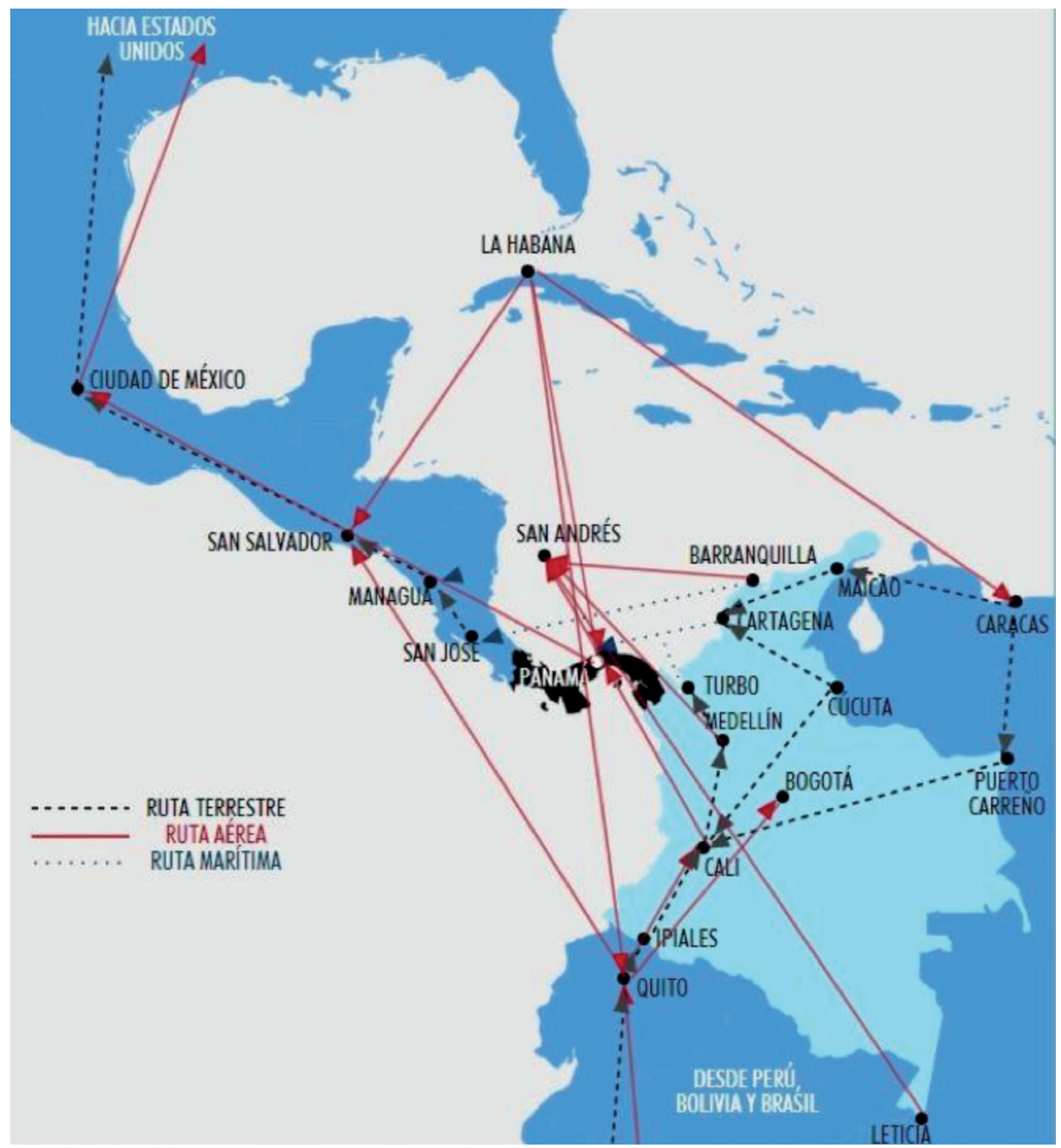

Fuentes: elaboración propia con base en Unidad Investigativa, "Así funciona la red que mueve 20 mil inmigrantes ilegales por Colombia", El Tiempo, 27 de septiembre de 2015, https://goo.gl/tZQ2AA (acceso mayo 25, 2018); UNODC, Dimensión del delito de tráfico de migrantes en Colombia, 23; Ocampo González y Arboleda, "Colombia y los flujos mixtos de migrantes", 102; "Estas son las rutas del tráfico de migrantes en Colombia". 


\section{Sugerencias y conclusiones}

Tras el análisis sobre la dualidad de la migración entre Colombia y Panamá —legal e ilegal- se abre paso a una serie de sugerencias cuyo propósito es contribuir a la propuesta de soluciones más eficaces frente a un problema tan complejo como el estudiado.

En primera medida, se puede elaborar un informe de evaluación que examine y dé cuenta de los avances en materia de capacitación de funcionarios en las instituciones pertinentes sobre el tráfico ilícito de migrantes en cuanto a la calidad y pertinencia de la información.

Se requiere una respuesta articulada de los Estados al problema del tráfico ilícito de migrantes, que salvaguarde los derechos humanos de las víctimas y no se trate desde la perspectiva de la seguridad nacional, máxime cuando en la última reunión de los jefes de Estado de Panamá y Colombia se sostuvo que su cooperación seguiría en torno a la facilitación de equipamiento militar, instalación de más bases militares binacionales e intercambio de inteligencia, con una preocupante ausencia del enfoque desde la seguridad humana. ${ }^{79}$

Además de atender las necesidades inmediatas que acarrea esta problemática, es de vital importancia comprender la cooperación bilateral como un elemento clave tanto para el fortalecimiento institucional como oportunidad para el desarrollo económico de la región de frontera y la consolidación de un espacio de cooperación internacional descentralizado, en el que se desarrolle un diálogo fluido entre las Administraciones locales y territoriales que son parte del entramado geográfico de la región.

Es pertinente incluir en el próximo plan nacional de desarrollo la temática del tráfico ilícito de migrantes y no solo sustentar el tema migratorio nacional desde el fomento de la migración laboral. Al identificar a los migrantes irregulares que son víctimas del tráfico ilícito, es imperativo recordarles su calidad de víctimas ${ }^{80}$ y el alcance —amplio, por lo demás- jurídico de los hechos que hacen que una persona sea considerada refugiado. ${ }^{81}$

\footnotetext{
79 "Colombia y Panamá reforzarán la frontera por flujo migratorio”, El Espectador, 25 de octubre de 2016, https://goo.gl/ER7RzQ (acceso mayo 25, 2018).

80 UNODC, Dimensión del delito de tráfico de migrantes en Colombia, 256.

81 Ocampo González y Arboleda, "Colombia y los flujos mixtos de migrantes", 106
} 
A manera de reflexión final, a pesar de que es claro que persiste la lógica dual de las migraciones colombianas hacia Panamá, es necesaria la asunción conjunta de responsabilidades entre Colombia y Panamá, en tándem con la Organización de Naciones Unidas, la Organización Internacional para las Migraciones y el alto comisionado de las Naciones Unidas para los refugiados, como un avance institucional y material para la gestión contra estos fenómenos.

A causa de los acontecimientos de gran relevancia como la firma de los acuerdos entre el Gobierno y las FARC en 2017, como un paso hacia la pacificación y la desarticulación de las actividades criminales en la región, tanto Colombia como Panamá deben preparar políticas de Estado que consoliden un manejo adecuado de las migraciones y la delincuencia organizada transnacional como posibles elementos conexos, con el fiel propósito de preservar los derechos humanos de los migrantes, quintaesencia de la cooperación internacional.

\section{Referencias}

"Así opera la mafia del tráfico de migrantes en Colombia". El País, 7 de agosto de 2016. https://goo.gl/TwEZgo (acceso mayo 25, 2018).

"Colombia y Panamá reforzarán la frontera por flujo migratorio". El Espectador, 25 de octubre de 2016. https://goo.gl/ER7RzQ (acceso mayo 25, 2018).

"Diputada panameña llamó 'escoria' a inmigrantes colombianos". Noticiascaracol.com, 24 de febrero de 2015. https://goo.gl/jQtyFp (acceso mayo 25, 2018).

"Dos funcionarios de migración entre 10 imputados por trata en Panamá". Las Américas, 30 de enero de 2017. https://goo.gl/DXa8TQ (acceso mayo 25, 2018).

"Estas son las rutas del tráfico de migrantes en Colombia". El País, 9 de noviembre de 2015. https://goo.gl/tzi7HX (acceso mayo 25, 2018).

"Frontera entre Colombia y Panamá no estará cerrada sino más controlada: Migración". RCN Radio, 10 de mayo de 2016. https://goo.gl/Pe4Gtz (acceso mayo 25, 2018).

"La frontera colombo-panameña: migración ilegal y drama de desplazados". Caracol Radio, 7 de febrero de 2017. https://goo.gl/pf8tdn (acceso mayo 25, 2018).

"Panamá decreta nuevo proceso de regularización migratoria". El Espectador, 3 de junio de 2016. https://goo.gl/WUi33s (acceso mayo 25, 2018).

"Panama's Perilous Jungle Is a New Route for Migrants". Wall Street Journal, 29 de mayo de 2015. https://goo.gl/fZ5v9o (acceso mayo 25, 2018).

Acuña, Guillermo, coord. Flujos migratorios laborales intrarregionales: situación actual, retos y oportunidades en Centroamérica y República Dominicana. San José: OIM, OIT, MTSS, CECC SICA, OCLAD, Red de Observatorios del Mercado Laboral, AECID, 2011. 
Arcia, José. "Residentes en Panamá, cerca de los 5 millones". La Estrella de Panamá, Secc. Nacional, 9 de junio de 2016. https://goo.gl/UrcKGC (acceso mayo 25, 2018).

Banco de la República. "Remesas". http://goo.gl/WLmq5b (acceso julio 17, 2018).

Cabrera, Irene. "Conflicto armado, criminalidad y violencia en la frontera colombo-panameña: elementos críticos para buscar una transición" en Fronteras en Colombia como zonas estratégicas: análisis y perspectivas, editado por Andrés Molano-Rojas, 221-244. Bogotá: Konrad Adenauer Stiftung, 2016.

Comisión Económica para América Latina [Cepal]. "Investigación de la migración internacional en Latinoamérica (Imila)". http://goo.gl/RkVkLf (acceso junio 25, 2018).

Comisión Económica para América Latina [Cepal]. "Red de datos para áreas pequeñas por microcomputador (Redatam)". https://goo.gl/fGIU58 (acceso junio 25, 2018).

Comisión Interamericana de Derechos Humanos. CIDH expresa profunda preocupación por situación de migrantes en Colombia, cerca de la frontera de Panamá. Comunicado No. 112/16. Washington, 8 de agosto de 2016.

Conniff, Michael. "Panamá desde 1903" en Historia de América Latina, vol. 15. América Central desde 1930, editado por Leslie Bethell, 247-279. Madrid: Crítica, 1997.

Departamento Administrativo Nacional de Estadística [DANE]. "Censo general 2005". https://www.dane.gov.co/index.php/estadisticas-por-tema/demografia-y-poblacion/ censo-general-2005-1 (acceso junio 29, 2018).

Departamento Nacional de Planeación [DNP]. "Dinámicas y flujos migratorios ColombiaPanamá: estado actual y perspectivas futuras". Bogotá: Autor, 2016.

LaSusa, Mike. "Panama's Colombia Border Closure Could Fuel Human Trafficking". Insight Crime, 10 de mayo de 2016. https://goo.gl/Q2vbKh (acceso mayo 25, 2018).

Ocampo González, Melina y Sebastián Arboleda. "Colombia y los flujos mixtos de migrantes en el derecho internacional de los refugiados”. Opinión jurídica 15, núm. 30 (2016): 93-108.

Oficina de las Naciones Unidas contra la droga y el delito [UNODC]. Dimensión del delito de tráfico de migrantes en Colombia: realidades institucionales, legales y judiciales. Bogotá: Autor, 2013.

Organización de Naciones Unidas [ONU]. Protocolo contra el tráfico ilícito de migrantes por tierra mar y aire. Nueva York, 12 de diciembre de 2000.

Organización de Naciones Unidas [ONU]. Protocolo para prevenir, suprimir y sancionar la trata de personas, especialmente mujeres y niños. Palermo, 15 de noviembre de 2000.

Organización de Naciones Unidas [ONU]. "Total International Migrant Stock Report by Country of Origin and Destination, 1990-2017". https://goo.gl/2tWzpi (acceso julio 6, 2018). 
Organización de Naciones Unidas [ONU]. "Total International Migrant Stock Report by Country of Origin and Destination, 1990-2017". https://goo.gl/2tWzpi (acceso julio 6, 2018).

Organización Internacional para las Migraciones [OIM] . Glosario sobre migración. Ginebra: Autor, 2006.

Organización Internacional para las Migraciones [OIM]. Estudio investigativo para la descripción y análisis de la situación de la migración y trata de personas en la zona fronteriza colombo-panameña. Bogotá: Autor, 2007.

Palma, Mauricio y Farid Badrán. "Crimen transnacional organizado y utilitarismo sociológico: evidencia desde el tráfico de personas en Colombia”. Oasis, núm. 25 (2017): 77-94.

Palma, Mauricio. "Ascenso, proliferación, gestión y icontrol? Tráfico de migrantes a través de las fronteras de Colombia en Fronteras en Colombia como zonas estratégicas: análisis y perspectivas, editado por Andrés Molano-Rojas, 93-114. Bogotá: Konrad Adenauer Stiftung, 2016.

Pujol, Acela. "La frontera colombo-panameña: una frontera selvática, cerrada al progreso pero abierta a las migraciones más disímiles". Estudios Fronterizos 40, núm. 4 (1997): 81-94.

Rampietti, Alessandro. "Migrants stranded in Colombia as route to US closed". AlJazeera, 7 de julio de 2016. https://goo.gl/ZGv6ro (acceso mayo 25, 2018).

República de Colombia. Código Penal. Bogotá: Legis, 2000.

Restrepo, Luis Guillermo. "Crisol de razas". El País, 1 de marzo de 2015. https://goo.gl/ NSVqQx (acceso mayo 25, 2018).

Sánchez Saavedra, Kevin. "Migración transfronteriza indígena en Darién, Panamá". Estudios Centroamericanos 699-700, núm. 3 (2007): 63-88.

Sánchez Saavedra, Kevin. "Migración y refugio en Panamá. Encuentro: revista académica de la Universidad Centroamericana 80, núm. 1 (2008): 97-107.

Schaefer, Sara. "A Dark, Deadly Path to the US. - Migrants from around the World Brave the Vipers, Bats and Bandits of Panama's Darien Gap to Reach America". Wall Street Journal, 29 de mayo de 2015. https://goo.gl/qTxXQi (acceso mayo 25, 2018).

Servicio Jesuita a Refugiados. "Panamá: la migración forzada desde la opinión pública". https://goo.gl/GoJWVU (acceso mayo 25, 2018).

Unidad Investigativa. "Así funciona la red que mueve 20 mil inmigrantes ilegales por Colombia”. El Tiempo, 27 de septiembre de 2015. https://goo.gl/tZQ2AA (acceso mayo 25, 2018).

Wyss, Jim. "Cuban Migrants Face Dangerous, Grueling Jungle Trip as Panama Clamps Down”. Miami Herald, 9 de mayo de 2016. https://goo.gl/ltLnY6 (acceso mayo 25, 2018). 